\title{
ENTERPRISE KNOWLEDGE MANAGEMENT BASED ON PLONE CONTENT MANAGEMENT SYSTEM
}

\author{
Chuanhong Zhou ${ }^{1}$, Huilan Zeng ${ }^{1}$ \\ ${ }^{\prime}$ CIMS \& Robot Center of Shanghai University, Shanghai University, China; Email: \\ chhzhou@staff.shu.edu.cn.
}

\begin{abstract}
This paper represented a convenient and perfect Knowledge management Information System for enterprises by introducing Knowledge Management (KM) strategy into Content Management System (CMS). A Universal model was put forth on KM under the platform of CMS. In addition, an approach was researched for knowledge Acquisition by classifying under RSS in order to build a perfect Knowledge Process System (KPS). Various functions on KM were performed based on PLONE CMS, which imply the essential of Enterprise Knowledge Management (EKM). This research has a good prospect either in terms of economy or availability.

Key words: Knowledge Management; PLONE; knowledge Acquisition; Knowledge Process System
\end{abstract}

\section{INTRODUCTION}

Learning mode and knowledge reserved in enterprises reveal their performance and competitiveness in the market. Today more and more enterprises come to realize the importance of knowledge after suffering these troubles, such as core staff turnover, leak of key technique and loss of numberless important persons; as a result, they begin to build their own Enterprise Knowledge Management System (EKMS) to sharp the advantage. $\mathrm{KM}$ is an important conception in conducting Enterprises management and Information management, and aims at improving their overall abilities to acquire, develop, preserve, distribute and utility knowledge. Each enterprise, however, must combine its own feature with system.

Please use the following format when citing this chapter:

Zhou, Chuanhong, Zeng, Huilan, 2006, in International Federation for Information Processing (IFIP), Volume 207, Knowledge Enterprise: Intelligent Strategies In Product Design, Manufacturing, and Management, eds. K. Wang, Kovacs G., Wozny M., Fang M., (Boston: Springer), pp. 115-120. 
Statistics shows, eighty percent of knowledge for many enterprises is hidden in the content directly or indirectly ${ }^{1}$, so Content Management (CM) becomes a precondition in launching KM. CMS is regard as a support platform of KM with good feasibility and economy. In this paper a general model is presented on KM based on CM, and in which various functions are displayed to realize EKM in manufacturing sector.

PLONE is recognized as the most outstanding charge-free, open-source CMS with many merits, such as great convenience, use safety and reliability, internationalization and standard, expansibility etc. A new Knowledge Classifying and Acquisition method is explained based on RSS (RDF Site Summary) in the paper to perfect KPS, so as to extend the significance of $\mathrm{KM}$ in manufacturing firms.

\section{UNIVERSAL MODEL OF KM BASED ON CM}

\subsection{Universal model of KM based on CMS}

Literally $\mathrm{CM}$ means management of content, and $\mathrm{KM}$ means management of knowledge. The integration of these two becomes a rising trend with development. Statistics shows, eighty percent of knowledge for many enterprises is hidden in the content directly or indirectly, so content can be regarded as memories of enterprises, $\mathrm{CM}$ becomes a precondition in launching KM, meanwhile enterprises can also reach their goals by $\mathrm{KM}$ with help of content. A Universal model is put forth on KM under the platform of CMS with good feasibility and economy. CMS, as a support platform of KM, can collect fundamental information KM needs, and analyze and integrate KM by classifying and searching.

EKM Portal mainly consists of four big modules: CM module, Business process model, Communication Management and Project Collaboration, Knowledge Asset Management and Management of Employees with knowledge. The former comprises Documentary Management and official automation management (OA), Template Management, Workflow Management and Safe Management. The second one comprises Marketing Management (center in customer's relation management (CRM)), Logistic and Purchase Management (center in supply chain management (SCM)), Production and Manufacture management (combining the workflow management under PDM (Product Data Management), PLM (Product Lifecycle Management), and ERP (Enterprise Resource Planning)). Communication Management includes virtual meeting, right-time message, public white board, BBS, short message, online meeting, etc. 
Knowledge in company helps take into shape group behavior, people can learn truth from their past experience and keep them in their common minds, working programs, rules or routine of company assets and activities ${ }^{2}$ These four models penetrate flow of knowledge, which is formed by depositing, sharing and communicating to add great value to enterprises. It is needed to build a perfect KPS and workflow management system in establishing EKM based on CMS in manufacturing sector. See Fig 1.

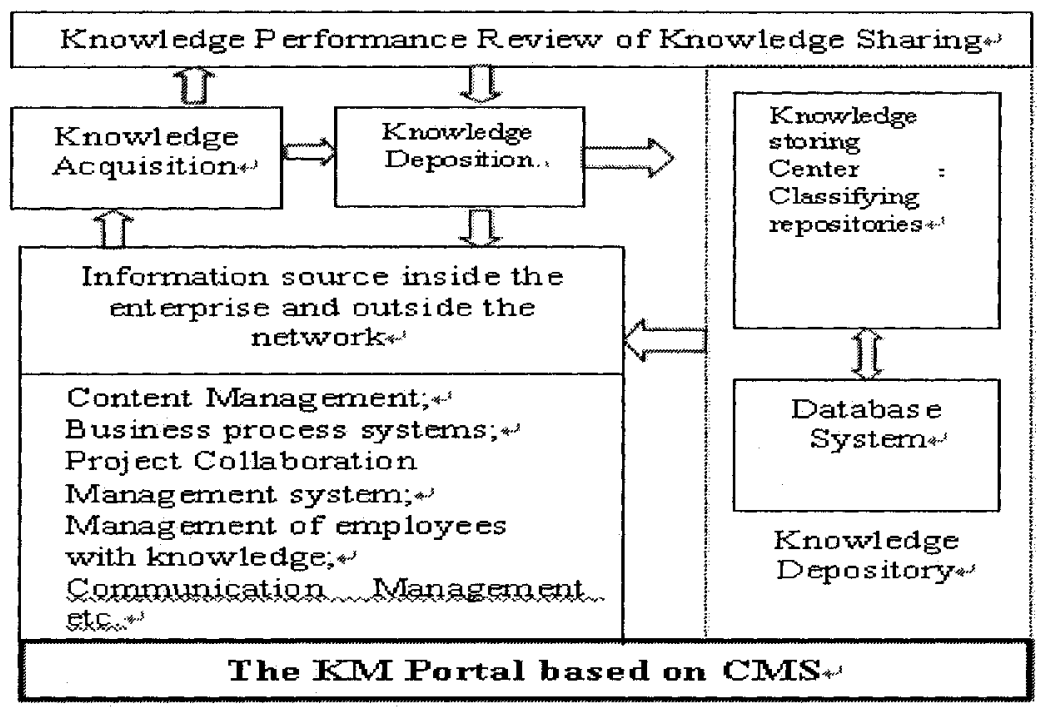

Figure 1. The Knowledge Process System model

\subsection{Knowledge Acquisition}

This paper presents two following crucial points in Knowledge Acquisition:

1. Knowledge Classifying and Acquisition mechanism establishment based on RSS: $\mathrm{RSS}^{3}$ norms can be used to solve the issue like news publication. RSS is among of XML application, and can offer some optional, summarized web content to terminal customers, by which you can subscribe updated information offline as well. This paper proposed a method of Knowledge Classifying and Acquisition based on RSS, customers can get what they need through filling the specified condition. Tons of information and scattered data in company bring tougher difficulties to administrators, therefore, we introduce administrators a new approach to get necessary information timely in the light of specific requirements. 
2. Collecting information outside of intranet by RSS: Users can read some refined materials and set latest time when not opening the web, giving that installing the third-party product BLOG (Weblog) in CMS, RSS can get BLOG information from outside timely, which is an elementary method to catch topics and latest information from BLOG.

\subsection{Knowledge Deposition}

Gathering all the knowledge is the first step to launch a campaign of KM in company, meanwhile collecting successful experiences and notorious lessons is necessary for enterprises so as to learn right from wrong. For this purpose, enterprises must come to change the model of handed Documentary Management to realize automation or semi-automation of business. Here three keys are pointed out to achieve this goal.

1) Knowledge classification system establishment: Based on current specified knowledge database, users must perfect their system consistently according to real situation, classify them respectively and issue them into the system timely.

2) A set of methodology put forth: Under different form, or knowledge, or environment, corresponding different measures should be taken.

The management of explicit knowledge: Make good use of current resources (such as instruction, various white papers, solution and proposal etc.) to neaten them and save into the relevant database in order to improve the efficiency and share of knowledge.

The management of tacit Knowledge: Motivate or force to realize the transition of knowledge from implicit to explicit. That valuable information kept in employee's minds, groups or special teams can be uncovered through BBS, knowledge motivation system, Knowledge Performance Review system, or specific review files or reports.

3) Knowledge Deposition by Knowledge Classifying and Acquisition mechanism: In this paper a new mechanism is established to acquire, deposit and retrieve knowledge ${ }^{4}$ routinely by RSS.

\section{KM PORTAL BASED ON PLONE}

Various functions are designed to realize EKM in manufacturing sector so as to build enterprise KPS based on PLONE CMS. PLONE, giving birth at 2000 , is advanced significantly and recognized as the most outstanding open-source CMS because of its strong function of ZOPE/CMF and the joint contribution from community leaders Limi and Runyan. PLONE CMS has many great virtues, such as convenience, safety and reliability, 
internationalization, accessibility, expansibility, strong searching power, customization etc, which make it successful to become the option for enterprises to set up EKM.

PLONE CMS offers overall function for Documentary Management and has perfect mechanism for privilege management. This paper proposes other functions in KM module by the following two aspects, 1. Utilize the colorful resources of the network, install the third plug-in (Products) of ZOPE or PLONE, in addition, you can also develop or create some requisite plug-in by PYTHON. 2. Strong workflow support is needed in KMS, the rule of workflow is built under OpenFlow, plug-in of ZOPE, which is a workflow management system based on activity and meets the criterion WFMC made. And what's more, visual workflow management system and workflow emulation system could be constructed based on PLONE so as to build perfect workflow management.

In the paper we take a case in a manufacturing company for example to explain KPS. Such items or processes are involved for most manufacturing enterprises, diagram papers, BOM (Bill Of Material) list, process planning, analysis model and result, cost structure, material specification, purchase price, training materials, knowledge forum, Email, message, and analysis report etc.

\subsection{Knowledge Classifying and Acquisition mechanism establishment based on RSS}

Knowledge Acquisition, a basis to deposition, includes in PLONE system, means of searching and filtering, RSS (RDF Site Summary), web navigation etc. In this paper, a classified searching system under RSS is initiated, which is a second-development package in Archetypes mechanism. Archetypes mechanism is a framework for developing new content types in PLONE.

Based on the above rule, customers can get what they need and create relevant dynamic RSS FEED through filling the specified condition. RSS Feed is a summary file about content of websites consisting of RSS elements. If typing a word like "machining" in "full text inquiry" of this Knowledge Classifying and Acquisition mechanism, the following result will be matched in RSS FEED format.

$<$ ?xml version $=" 1.0$ " encoding $=$ "utf- 8 " ?>

-<rdf:RDF xmlns:rdf="http://www.w3.org/1999/02/22-rdf-syntaxns\#"

$\mathrm{xmlns}: \mathrm{dc}=$ "http://purl.org/dc/elements/1.1/"

xmlns:sy="http://purl.org/rss/1.0/modules/syndication/"

$\mathrm{xmlns}=$ "http://purl.org/rss/1.0/">

$<$ channel rdf:about="..."> 


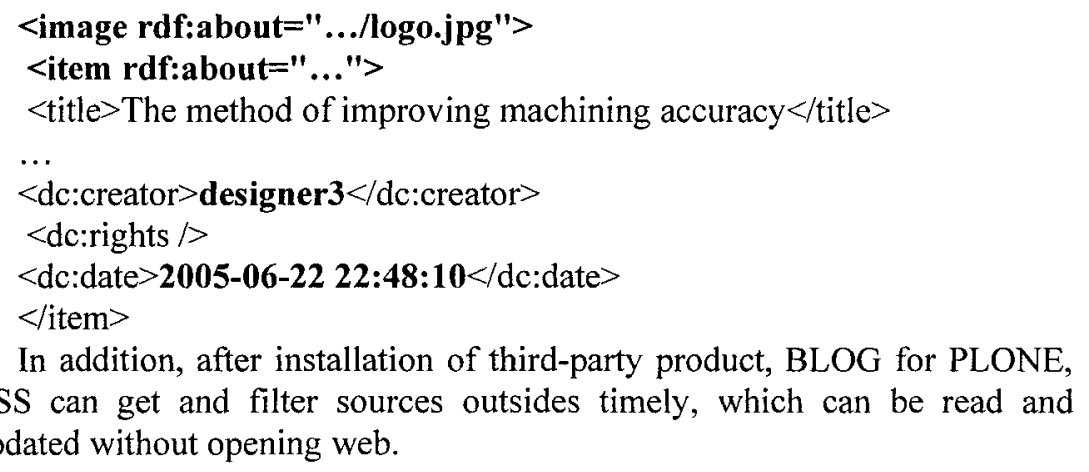

\subsection{Knowledge Deposition}

In this paper a new mechanism is established to acquire, deposit and retrieve knowledge routinely by RSS, system can get processing information regularly and timely and produce relative RSS FEED, which can be produced automatically by system, or also made manually. Then RSS FEED will be transformed into visual format and added into knowledge depositary.

\section{CONCLUSION}

In this paper a universal model of KM based on CM is put forward, and combined closely with business to build a EKMS based on PLONE CMS. This model can be introduced into various industries to establish related EKMS in order to run their business more efficiently. Furthermore, it also shows good accessibility to integrate with some prominent software for enterprise management, such as PLM, ERP.

\section{REFERENCES}

1. Thiruvathukal, G.K.; Laufer, K.; Plone and content management, Computing in Science \& Engineering, Volume 06, Issue 4, July-Aug. (2004), pp. 88 - 95.

2. GAO Tianzhen, Model Framework of Knowledge Management System and the Analysis of the Key Problem in the Process of Knowledge Management Enforcement, SCIENCE OF SCIENCE AND MANAGEMENT OF S.\& T, (2005), (3),pp. 69-72 (in Chinese).

3. Yuan Yongzhi, The Technology of Web Information Release and Integration Based on RSS, New technology of library and information service, (2004), (2),pp.60-62 .

4. Li Rong, A brief study on setting up an assessment mechanism of knowledge sharing, BEIJING TECHNOLOGY AND BUSINESS UNIVERSITY(SOCIAL SCIENCE), (2005), Vol.20, No.2, pp. 4 I-44 (in Chinese). 